\title{
KUAT TEKAN BETON POLIMER BERBAHAN ABU VULKANIK GUNUNG SINABUNG DAN RESIN EPOKSI
}

\author{
Yulius Rief Alkhaly, Cok Nando Panondang ${ }^{1)}$, Zulfahmi ${ }^{2)}$ \\ ${ }^{1)}$ Jurusan Teknik Sipil, ${ }^{2)}$ Jurusan Teknik Mesin, Fakultas Teknik, Universitas Malikussaleh \\ email:yr.alkhaly@gmail.com
}

\begin{abstract}
Abstrak
Beton polimer merupakan suatu jenis beton yang terbuat dari bahan polimer sebagai binder penggati semenportland. Dibanding dengan semen portland, beton yang terbuat dari polimer relatif lebih baik dalam hal: kuat tekan, stabilitas volume, dan durabilitas.Pada penelitian ini, semen Portland tipe I merk Andalas sebagai binderdisubstitusi dengan kombinasi abu vulkanik Gunung Sinabung (AV) dan resin epoksi (RE) sebagai material polimer.Agregat kasar dan agregat halus dipakai berupa kerikil dan pasir sungai. Benda uji beton dicetak menggunakan silinder berukuran $150 \mathrm{~mm}$ x $300 \mathrm{~mm}$ untuk masing-masing variasi polimer sebanyak 5 sampel dan untuk beton normal 5 sampel. Adapun kombinasi variasi polimer yang digunakan adalah: (5\% AV+ $5 \% R E)$, (12\% AV + 7\% RE), dan(25\% AV + 10\% RE) dengan mutu beton normal rencana sebesar 17,50 MPa. Hasil penelitian memperlihatkan bahwa besarnya kuat tekan yang dihasilkan untuk masing-masing variasi di atas secara berutan adalah: 14,83 MPa, 22,53 MPa dan 25,36 MPa, sedangkan beton normal memiliki kuat tekan sebasar 18,74 MPa. Kombinasi variasi $(12 \%$ AV + $7 \% R E) \operatorname{dan}(25 \% A V+10 \%$ RE) memberi hasil kuat tekan lebih baik dibanding beton normal, masing-masing meningkat sebesar 20,22\% dan 35,32\%. Hal ini menunjukkan bahwa peningkatan kuat tekan dapat dicapai dengan menggunakan kombinasi polimer lebih besar dari 5\%.
\end{abstract}

Kata kunci: kuat tekan,beton polimer, abu vulkanik, resin epoksi.

\section{Pendahuluan}

Sejak semen ditemukan oleh Joseph Aspidin pada awal abad ke 19, penggunaannya dalam industri rekayasa konstruksi semakin meningkat pesat, hal tersebut dipengaruhi oleh kebutuhan bangunan modern yang umumnya menggunakan beton sebagai material strukturnya. Secara tipikal, beton diproduksi dengan menggunakan $12 \%$ semen, $8 \%$ air, dan $80 \%$ agregat berdasarkan beratnya. Hal ini memberi gambaran bahwa untuk memproduksi beton di seluruh dunia telah dipakai semen sebanyak 1,6 milyar ton, agregat (pasir dan batuan) 10 milyar ton, dan air 1 milyar ton. Selain itu jumlah agregat yang digunakan untuk pembuatan klinker semen mencapai 12,6 milyar ton (Mehta, P. K., 2002). Keseluruhan proses produksi beton ini memberikan dampak buruk pada ekologi dan konsumsi energi di bumi, setiap tahunnya menghasilkan 1,35 milyar ton emisi gas rumah kaca atau berkontribusi sebesar 7\% dari total emisi gas rumah kaca yang diproduksi dari industri-industri modern (Malhotra, V.M.,2002,).

Demi menanggulangi permasalahan tersebut, banyak penelitian telah dilakukan dalam upaya untuk mengurangi penggunaan semen dan bahan alam pada pembuatan beton sehingga menghasilkan beton yang ramah lingkungan. Upaya tersebut meliputi rekayasa material dan rekayasa proses produksi. Salah satu jalan untuk mendapatkan beton ramah lingkungan adalah dengan 
menggunakan bahan alternatif seperti bahan polimer sebagai binder penggati sebagian atau keseluruhan semen. Bahan polimer kini mulai banyak dikembangkan, kinerja dan perilaku beton berbahan binder polimer berbeda dengan binder semen portland. Material beton normal yang dikombinasikan dengan bahan polimer akan menghasilkan sifat fisis dan sifat mekanis yang baik pada beton sehingga memberikan harapan bagi aplikasinya pada desain struktural (Ohama Y. O. M., dan Kumagai S. O. M., 2006).

Pada penelitian ini, binder polimer dibuat dari abu vulkanik dan resin epoksi, dan pengujian hanya berfokus pada sifat mekanik kuat tekan. Semen Portland tipe I disubstitusi dengan kombinasi abu vulkanik Gunung Sinabung $(\mathrm{AV})$ dan resin epoksi (RE) sebagai material polimer dengan variasi (5\% AV + $5 \% \mathrm{RE}),(12 \% \mathrm{AV}+7 \% \mathrm{RE})$, dan $(25 \% \mathrm{AV}+10 \% \mathrm{RE})$ dengan mutu beton normal rencana sebesar 17,50 $\mathrm{MPa}$.

\section{Tinjauan Kepustakaan}

\subsection{Beton Polimer}

Beton polimer adalah bahan komposit yang menggunakan polimer sebagai pengikat untuk mengganti keseluruhan atau sebagian semen. Beton polimer diperkenalkan pada akhir 1950-an dan menjadi terkenal pada 1970-an yang digunakan untuk material perbaikan (repairing), dan komponen beton pra-cetak. Produk tersebut dikenal sebagai beton resin sintetis, atau resin beton, ataupun beton resin plastik (Blaga, A. dan Beaudoin, J. J., 1985)

Alasan utama digunakan beton polimer pada beberapa aplikasi konstruksi adalah karena kekuatannya yang tinggi dan bobotnya yang ringan dibanding binder semen portland. Selain itu, beton polimer tahan terhadap bahan kimia, tahan korosi, penyerapan air rendah, dan stabilitas pemadatan tinggi, serta proses pengerasan dapat dipersingkat hanya beberapa jam saja (Mikhailov, K.V., et. al., 1992).

Ide penggunaan bahan polimer organik sebagai bahan konstruksi telah dikenal ribuan tahun yang lalu. Hal ini diketahui bahwa pada awal sejarah peradaban, manusia telah menggunakan kombinasi polimer alami dengan meterial inorganik untuk memproduksi material berkekuatan dan berdurabilitas tinggi, misalnya: (1) Pada abad ke-4 sebelum masehi (S.M.), dinding batu bata tanah liat Babilonia dibangun menggunakan polimer alam 'mortar aspal'. Mortar bitumen dalam konstruksi juga ditemui di kota-kota lembah Indus dari Mohenje-daro dan Harappa sekitar 3.000 S.M. dan dekat Tigris di 1.300 S.M. Banyak polimer alam termasuk albumin, darah, dan pasta beras telah digunakan dalam pembuatan mortar kuno. (2) Hal ini juga dipercaya bahwa pada awal abad ke-2 mesehi, mortar dari pasta kapur beras ketan digunakan untuk membangun tembok Besar China (You-Yun, W., 1981).

\subsection{Abu Vulkanik}

Material vulkanik merupakan mineral batuan vulkanik termasuk material glass yang memiliki ukuran sebesar pasir dan kerikil dengan diameter kurang lebih $2 \mathrm{~mm}$. Partikel abu vulkanik sangat kecil, umumnya dapat memiliki 
penampang lebih kecil dari 0,001 mm.Abu vulkanik terbentuk selama erupsi vulkanik secara eksplosif gunung berapi. Abu vulkanik bukan merupakan produk pembakaran seperti abu terbang yang lunak dan halus seperti hasil pembakaran kayu, daun atau kertas.Abu vulkanik memiliki sifat sangat keras dan tidak larut di dalam air sehingga seringkali sangat abrasive dan sedikit korosif serta mampu menghantarkan listrik ketika dalam keadaan basah (Bayuseno,A. P., 2010).

Abu vulkanik (AV) mengandung silika $\left(\mathrm{SiO}_{2}\right)$ relatif tinggi, sifat fisik dan kimianya sesuai dengan ASTM C618-93, spesifikasi Standar fly ash dan bahan alam pozzolan kalsinasi untuk digunakan sebagai Mineral Admixturepada betonsemen portland (Siddique, R., 2011). Tipikal kandungan abu vulkanik diperlihatkan pada tabel berikut:

Tabel 1 Tipikal Komposisi Kimia Abu Vulkanik

\begin{tabular}{|l|c|}
\hline \multicolumn{1}{|c|}{ Senyawa Kimia } & Jumlah $(\%)$ \\
\hline Kalsium Oksida $(\mathrm{CaO})$ & 6,10 \\
\hline Silika $\left(\mathrm{SiO}_{2}\right)$ & 59,32 \\
\hline Alumina $\left(\mathrm{Al}_{2} \mathrm{O}_{3}\right)$ & 17,50 \\
\hline Besi Oksida $\left(\mathrm{Fe}_{2} \mathrm{O}_{3}\right)$ & 7,06 \\
\hline Sulfur Trioksida $\left(\mathrm{SO}_{3}\right)$ & 0,71 \\
\hline Magnesia $(\mathrm{MgO})$ & 2,55 \\
\hline Natrium Oksida $\left(\mathrm{Na}_{2} \mathrm{O}\right)$ & 3,80 \\
\hline Kalium Oksida $\left(\mathrm{K}_{2} \mathrm{O}\right)$ & 2,03 \\
\hline Hilang Pijar & 1,00 \\
\hline
\end{tabular}

Sumber: Siddique, R., 2011

\subsection{Resin Epoksi}

Resin epoksi (RE) adalah polimer dari kelompok termoset yang mengandung gugus epoksi, yakni gugus berisi atom oksigen yang terikat pada dua atom karbon berdampingan. Resin ini banyak digunakan sebagai perekat, karena mempunyai beberapa keunggulan, antara lain: tidak berubah kekuatannya walaupun telah bertahun-tahun, tahan terhadap minyak, alkali, pelarut aromatik, asam, alkohol, juga cuaca panas maupun dingin. Pemakaiannya juga cukup luas, pada bahan-bahan logam, gelas, keramik, dan kayu. Pada beton penggunaan resin epoksi dapat mempercepat proses pengeringan, karena epoksi menimbulkan panas sehingga membantu percepatan pengerasan (Gemert,D. V.,et. al., 2004).

\section{Metode Penelitian}

\subsection{Material}

Untuk pembuatan beton normal, agregat yang digunakan berupa pasir dan kerikil, keduanya merupakan material alam yang ditambang dari sungai Krueng Mane dan sungai Krueng Sawang, Kecamatan Muara Batu, Kabupaten Aceh Utara. Hasil analisa saringan agregat diperlihatkan pada Tabel 2.Sedangkan untuk pembuatan beton polimer, abu vulkanik yang digunakan merupakan dari hasil erupsi Gunung Sinabung di desa Ndokum Siroga, Kecamatan Simpang Empat, Kabupaten Karo.Komposisi kimia abu vulkanik Gunung Sinabung pada penelitian ini tidak diuji. Resin epoksi yang digunakan berupa general purpose resin epoxy(Bisphenol A - Epichlorohydrin) EPR 174, merek Eposchon®, produksi PT. Justus Kimia Raya (Gambar 1). Resin epoksi ini memiliki berat jenis 1,19. 


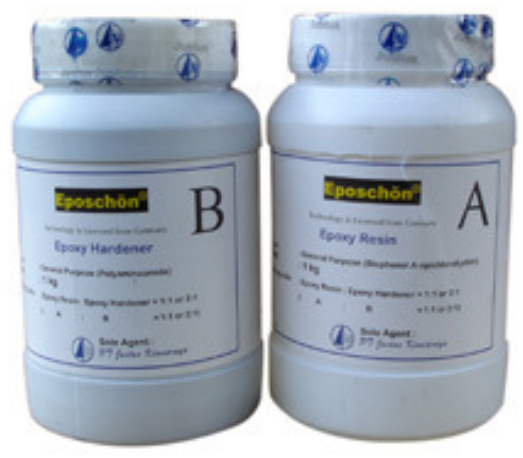

Gambar 1 Kemasan resin epoksi Eposchon ${ }^{\circledR}$

Sumber: http://203.21.74.28/pdimage/42/3955142_08032012095920_eposchon_a_b.jpg

Tabel 2 Analisa saringan agregat

\begin{tabular}{|c|c|c|}
\hline \multirow{2}{*}{$\begin{array}{c}\text { Ukuran saringan } \\
(\mathrm{mm})\end{array}$} & \multicolumn{2}{|c|}{ \% Lolos } \\
\cline { 2 - 3 } & Pasir & Kerikil \\
\hline 38,10 & 100 & 100 \\
\hline 19,00 & 100 & 94,64 \\
\hline 12,7 & - & 62,00 \\
\hline 9,50 & 99,60 & 51,76 \\
\hline 4,75 & 93,30 & 0 \\
\hline 2,36 & 87,64 & 0 \\
\hline 1,18 & 67,78 & 0 \\
\hline 0,60 & 44,62 & 0 \\
\hline 0,30 & 16,31 & 0 \\
\hline 0,15 & 4,90 & 0 \\
\hline Modulus halus butir & 2,80 & - \\
\hline
\end{tabular}

Sifat fisis lainnya dari agregat diperlihatkan dalam tabel berikut:

Tabel 3 Sifat fisis agregat

\begin{tabular}{|c|c|c|c|}
\hline \multicolumn{2}{|c|}{ Uraian } & Pasir & Kerikil \\
\hline Ukuran maksimum (mm) & 4,75 & 19 \\
\hline \multirow{2}{*}{ Berat } & Kering jenuh-permukaan & 2,53 & 2,52 \\
\cline { 2 - 4 } Jenis & Kering tungku/oven & 2,47 & 2,47 \\
\hline Absorpsi (\%) & 2,95 & 2,04 \\
\hline \multicolumn{2}{|l|}{ Kadar lembab (\%) } & 1,51 & 0,6 \\
\hline
\end{tabular}

Semen yang digunakan adalah produksi PT. Semen Padang, Portland Cement tipe I, dan air yang digunakan berasal dari Laboratorium Teknik Sipil, Universitas Malikussaleh. Untuk semen dan air tidak dilakukan pemeriksaan lagi, karena telah memenuhi persyaratan.

\subsection{Benda Uji Beton}

Benda uji beton dibuat sebanyak 20 buah berbentuk silinder dengan ukuran $150 \mathrm{~mm} \times 300 \mathrm{~mm}$, masing-masing 5 buah untuk setiap variasi beton. Faktor air semen sebesar 0,5. Proporsi campuran (mix design) dirancangberdasarkan SNI 03- 
2834-2000: Tata Cara Pembuatan Rencana Campuran Beton Normal. Tabel berikut memperlihatkan proporsi campuran untuk masing-masing variasi beton:

Tabel 4 Proporsi campuran beton

\begin{tabular}{|c|c|c|c|c|c|c|c|c|c|}
\hline \multirow[b]{2}{*}{ No } & \multirow{2}{*}{ Jenis Beton } & \multirow{2}{*}{$\begin{array}{c}\text { Variasi } \\
(\mathrm{AV}+\mathrm{RE}) \\
\% \\
\end{array}$} & \multirow{2}{*}{$\begin{array}{l}\text { Benda } \\
\text { uji (bh) }\end{array}$} & \multicolumn{6}{|c|}{ Proporsi per $\mathrm{m}^{3}$ beton $(\mathrm{kg})$} \\
\hline & & & & Air & Semen & Pasir & Kerikil & $\mathrm{AV}$ & $\mathrm{RE}$ \\
\hline 1 & Beton Normal & $(0+0)$ & 5 & 207,7 & 390,00 & 700,43 & 981,90 & - & - \\
\hline 2 & Beton Polimer A & $(5+5)$ & 5 & 207,7 & 368,40 & 700,43 & 981,90 & 15,43 & 7,46 \\
\hline 3 & Beton Polimer B & $(12+7)$ & 5 & 207,7 & 341,00 & 700,43 & 981,90 & 36,99 & 10,43 \\
\hline 4 & Beton Polimer C & $(25+10)$ & 5 & 207,7 & 290,83 & 700,43 & 981,90 & 77,18 & 14,93 \\
\hline
\end{tabular}

\subsection{Penyiapan dan Perawatan Benda Uji}

Pengadukan material dilakukan dengan bantuan mesin molen, material dimasukkan ke molen secara bertahap. Pengadukan dihentikan setelah material tercampur dengan baik dan terlihat telah homogen yang dapat diidentifikasi berdasarkan warna adukan telah sama seluruhnya. Selanjutnya dilakukan permeriksaan tingkat kemudahan pengerjaan(workablity) berdasarkan pengujian slump dan kemudian adukan di cor ke dalam cetakan silinder besi.

Setelah berumur 1 hari, benda uji silinder beton dikeluarkan dari cetakan. Penyimpanan dan perawatan benda uji dilakukan dengan cara perendaman di dalam air pada suhu ruangan. Setelah masa perawatan berakhir, maka dilakukan pengujian kuat tekan beton arah vertikal silinder sampai benda uji hancur.Tiaptiap variasibeton diuji pada umur 28 hari.

\section{$4 \quad$ Hasil dan Pembahasan}

\subsection{Pengukuran Tinggi Slump}

Pengukuran tinggi slump dilakukan untuk mengetahui tingkat kemudahan pengerjaan, target slump rencana sesuaimix design adalah $25 \mathrm{~mm}-100 \mathrm{~mm}$. Metode pengujian slump mengacu pada standar American Society for Testing and Materials (ASTM) C 143/C 143M - 03. Adapun hasil pengukuran tinggi slump untuk masing-masing variasi benda uji adalah sebagai berikut:

Tabel 5 Nilai slump adukan beton

\begin{tabular}{|c|l|c|c|}
\hline No & Jenis Beton & Kode & $\begin{array}{c}\text { Rerata } \\
\text { Tinggi } \\
\text { Slump }(\mathrm{mm})\end{array}$ \\
\hline 1 & Beton Normal & BN & 60 \\
\hline 2 & Beton Polimer A & BPA & 50 \\
\hline 3 & Beton Polimer B & BPB & 40 \\
\hline 4 & Beton Polimer C & BPC & 50 \\
\hline
\end{tabular}

Tabel 5 memperlihatkan bahwa tinggi slump untuk seluruh variasi beton telah memenuhi slump rencana.Kandungan AV dan RE memberi dampak pada turunnya nilai slump.

\subsection{Pengujian Kuat Tekan}

Pengujian kuat tekan beton dilakukan pada saat benda uji berumur 28 hari, dengan kuat tekan yang direncanakan (f'c) sebesar 17,5 MPa. Dari hasil pengujian 
didapat nilai kuat tekan untuk setiap variasi beton sebagaimana diperlihatkan pada Tabel 6 dan Gambar 2.

Tabel 6 Kuat tekan masing-masing variasi jenis beton

\begin{tabular}{|c|l|c|c|c|c|c|}
\hline \multirow{2}{*}{ No } & Jenis Beton & Kode & AV & RE & $\begin{array}{c}|c| \\
\text { Kuat Tekan } \\
5 \text { sampel } \\
\text { (MPa) }\end{array}$ & StandarDeviasi \\
\hline 1 & Beton Normal & BN & 0 & 0 & 18,74 & 0,904 \\
\hline 2 & Beton Polimer A & BPA & 5 & 5 & 14,83 & 0,738 \\
\hline 3 & Beton Polimer B & BPB & 12 & 7 & 22,53 & 0,930 \\
\hline 4 & Beton Polimer C & BPC & 25 & 10 & 25,36 & 1,227 \\
\hline
\end{tabular}

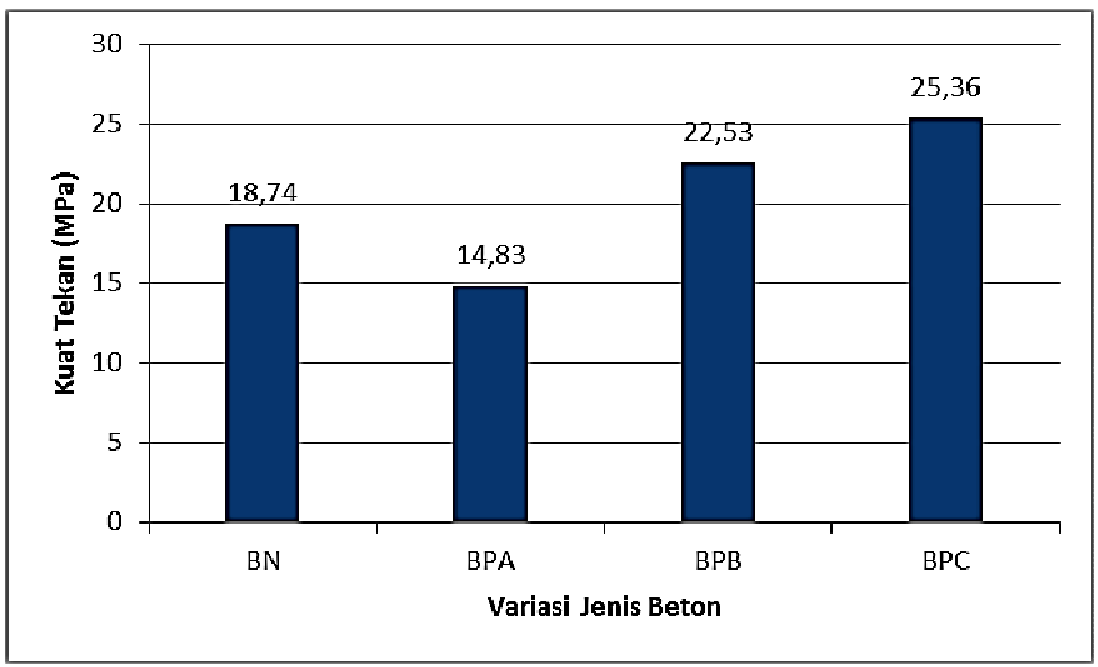

Gambar 2 Kuat tekan masing-masing variasi jenis beton

Berdasarkan Tabel 6 dan Gambar 2 di atas, nilai kuat tekan beton normal (BN) dengan fas 0,5 diperoleh sebesar $18,74 \mathrm{MPa}$ dan nilai ini memenuhi kuat tekan rencana dari mix design yang dibuat. Pada substitusi variasi kombinasi $5 \%$ AV dan 5\% RE(BPA) nilai kuat tekannya didapat $14,83 \mathrm{MPa}$, atau menurun sebesar 20,86\% dari kuat tekan BN. Penurunan ini menunjukkan bahwa pada taraf substisusi sebesar 5\%, binder polimer belum mampu memberikan ikatan/lekatan pada agregat yang sama seperti binder semen sehingga mengakibatkan beban yang dapat dipikul menjadi lebih rendah. Sebaliknya, terjadi peningkatan kuat tekan pada variasi kombinasi substitusi 12\% AV dan7\% RE (BPB) sebesar 20,22\% atau meningkat sebesar 3,79 MPa dari BN. Peningkatan kuat tekan yang sangat signifikan terjadi pada beton polimer substitusi $25 \%$ AV dan $10 \%$ RE (BPC) dengan peningkataan kuat tekan sebesar 35,33\% atau bertambah sebesar 6,62 MPa dari nilai kuat tekan BN. 
Dari uraian di atas, dapat diketahuibahwa penggunaan kombinasi abu vulkanik Gunung Sinabung dan resin epoksi memberi pengaruh yang baik terhadap kuat tekan beton apabila substitusi kombinasi keduanya lebih besar dari 5\% terhadap berat semen. Dengan demikian, beton polimer berbahan abu vulkanik dan resin epoksi ini memiliki potensi untuk dimanfaatkan pada kontruksi beton karena telah memenuhi syarat kuat tekan sebagai beton struktural (f'c $>17$ $\mathrm{MPa})$.

\section{$5 \quad$ Kesimpulan dan Saran}

\subsection{Kesimpulan}

Hasil yang diperoleh menunjukkan bahwa campuran abu vulkanik dan resin epoksi memiliki karakteristik yang baik dan cocok untuk pengganti parsial semen portland dalam campuran beton. Kesimpulannya kombinasi abu vulkanik erupsi Gunung Sinabung dapat digunakan dalam penggantian sebagian semen portlanddengan kadar kombinasi di atas 5\% terhadap berat semen untuk menghasilkan beton struktural.

\subsection{Saran}

Perlu adanya penelitian lanjutan dengan variasi abu vulkanik dan resin epoksi yang berbeda, untukmendapatkan nilai kuat tekan yang optimal.

\section{Daftar Kepustakaan}

Anonim, 2002, SNI 03-2834-2002: Tata Cara Pembuatan Rencana Campuran Beton Normal, Badan Standarisasi Nasional Indonesia;

Anonim, 2003, American Society for Testing and MaterialsC143/C 143M 03:Standard Test Method for Slump of Hydraulic-Cement Concrete, ASTM International, United States;

Bayuseno, A. P., et. al., 2010.Sintesis Semen Geopolimer Berbahan Dasar Abu Vulkanik Dari Erupsi Gunung Merapi, Rotari, Vol. 12 No. 4, pp. 10-16, Universitas Dipenogoro;

Blaga, A., dan Beaudoin, J. J., 1985.Polymer Concrete, Canadian Building Digest published;

Gemert,D. V., et. al., 2004, Cement Concrete and Concrete-Polymer Composites: Two Merging Worlds, A report from $11^{\text {th }}$ ICPIC Congress in Berlin;

Malhotra, V.M.,2002,Introduction: Sustainable Development and Concrete Technology, ACIConcrete International, Vol. 24 No. 7, pp. 22;

Mehta, P. K., 2002, Greening of the Concrete Industry for Sustainable Development, ACI Concrete International, Vol. 24 No. 7, pp.23-28; 
Mikhailov, K. V., et. al., 1992, Polymer concretes and their structural uses, Oxford \& IBH Publishing Co. Pvt. Ltd., New Delhi, No. 1, pp. 311-317;

Ohama Y. O. M., dan Kumagai S. O. M., 2006,Strength development and epoxy resin-cement interaction in hardened-free epoxy-modified mortars. In: Brandt AM, Li VC,Marshall LH (eds) Proceedings of International SymposiumOn Brittle Matrix Composites 8. ZTUREK RSI and WoodheadPublication, Warsawa, pp. 315-322;

Siddique, R., 2011, Review: Effect of volcanic ash on the properties of cement paste and mortar, Resources, Conservation and Recycling Vol. 56 pp. 6670 ;

You-Yun, W., 1981, Research and application of polymer concrete in China, Proceedings of The $3^{\text {rd }}$ International Congress on Polymers in Concrete, Nihon University, Koriyama, Japan, pp. 46-55; 